\title{
Estudo da Concentração de Mercado ao Longo da Cadeia Produtiva da Soja no Brasil
}

\author{
The Market Concentration in the Brasilian Supply Chain of Soybean
}

\author{
Nilson Luiz Costa ${ }^{1}$ \\ Antônio Cordeiro de Santana ${ }^{2}$
}

\begin{abstract}
Resumo: O objetivo da presente pesquisa foi mensurar a concentração de mercado ao longo da cadeia produtiva da soja. A partir dessas informações tornou-se possível avaliar se as estratégias para manter e ampliar o poder de mercado e a governança ao longo da cadeia produtiva da soja resultam em sucesso, captação do excedente do produtor rural de soja e competitividade da agroindústria processadora do grão. Neste contexto, foram calculados o Market Share, a Relação de Concentração e do Índice de Herfindahl-Hirschmann. Confirmou-se a hipótese de que o mercado que fornece insumos para os produtores rurais de soja está altamente concentrado. A hipótese de elevada concentração no segmento de aquisição e processamento da soja também foi confirmada. Concluiu-se que o produtor rural de soja encontra-se em situação de fragilidade econômica, pois: a) adquire insumos em mercado oligopolizado e vende a produção em mercado oligopsonizado; b) as empresas dominantes estão protegidas por barreiras à entrada. Diante deste cenário e das análises realizadas, cabe ao Estado brasileiro definir a forma de inserção dos agentes nacionais, em especial do produtor rural: se será caracterizado como um instrumento de acumulação do capital internacional ou se participará dos ganhos e se constituirá como agente de desenvolvimento regional.
\end{abstract}

Palavras-Chave: Concentração de Mercado, Cadeia Produtiva da Soja, Brasil.

\begin{abstract}
The aim of this research was to measure market concentration in brazilian supply chain of soybean. From this information it became possible to assess whether strategies to maintain and increase market power and governance throughout the soybean production chain resulted in success of the industry. In this context, we calculated the Market Share, Concentration Ratio and the Herfindahl-Hirschmann index. The hypothesis that the market that provides inputs to farmers Soy is highly concentrate was confirmed. The hypothesis of high concentration in the segment acquisition and processing of soybeans was also confirmed. It was concluded that farmers Soybean is in a situation of economic weakness, since a) acquires inputs in oligopolistic market and sell the production oligopsonistic market; b) dominant firms are protected by barriers to entry. Given this scenario and the performed analysis, it is the Brazilian state define the type of participation of national stakeholders, especially the farmers: whether it is characterized as an instrument of accumulation of international capital or participate in the gains and will constitute as a development agent regional.

Keywords: Market Concentration, Soybean Production Chain, Brazil
\end{abstract}

JEL: D21, D42, D43

\footnotetext{
${ }^{1}$ Economista. Doutor em Ciências Agrárias pela UFRA. Professor da Universidade Federal de Santa Maria (UFSM). nilson.costa@ufsm.br

2 Agrônomo. Doutor em Economia Aplicada pela UFV. Professor da Universidade Federal Rural da Amazônia (UFRA) e do Núcleo de Altos Estudos Amazônicos (NAEA) da Universidade Federal do Pará (UFPA). acsantana@superig.com.br
} 


\section{INTRODUÇÃO}

Dada a importância da cadeia produtiva da soja para a segurança alimentar doméstica e internacional, a economia, a geração de renda e exportações do agronegócio brasileiro, o estudo sobre suas potencialidades e fragilidades se constitui como uma ferramenta estratégica para pensar em políticas que favoreçam o ambiente competitivo e concorrencial e tornem a atividade sojícola em uma propulsora do desenvolvimento econômico nas regiões produtoras. Nesta perspectiva, o conhecimento científico deve extrapolar as contribuições que apresentam as limitações de caráter físico e de logística como determinantes da competitividade da soja brasileira, a exemplo de importantes estudos como os Ojima e Yamakami (2006), e avançar em análises que mensurem os efeitos da elevada concentração de mercado para a competitividade do produtor rural de soja.

Postula-se que os problemas econômicos básicos (o que produzir? Quando produzir? Como produzir? para quem produzir?) podem ser resolvidos pela livre concorrência. Entretanto, nem sempre existe livre concorrência e o equilíbrio dado pelo mercado pode representar uma solução não ótima, sobretudo porque nem todos os agentes dominam as informações e a estrutura de poder é diferenciada no sistema econômico.

Para abordar esse problema, a partir de dados relacionados à capacidade produtiva e comercialização, calcularam-se três indicadores de concentração: Market Share, Razão de Concentração e Índice de HerfindahlHirschmann. O cômputo desses indicadores, somadas às análises da estrutura de mercado e das limitações à concorrência, permitiu quantificar o poder de mercado das principais organizações da cadeia produtiva, o que revelou que a viabilidade econômica da produção de soja está submetida à governança de poucas empresas que se posicionaram, estrategicamente, à montante e jusante da produção.

Assim sendo, o presente estudo tem por objetivo analisar os mercados de fatores e de produtos e quantificar o poder das empresas nos segmentos que fornecem insumos e demandam a produção de soja.

O artigo está dividido em cinco seções, considerando-se a introdução. $\mathrm{Na}$ seção 2 é apresentado uma breve discussão teórica acerca do agronegócio. A seção 3 contempla os aspectos metodológicos, a descrição das variáveis utilizadas na construção dos indicadores e os parâmetros para análise do poder de mercado ao longo da cadeia produtiva. A seção 4 apresenta a análise da concentração de mercado à montante e jusante da cadeia produtiva, por segmento analisado. Por fim, a seção 5 apresenta as conclusões e recomendações do trabalho.

\section{AGRONEGÓCIO, CADEIAS PRODUTIVAS E VANTAGENS COMPETITIVAS}

Entre as principais abordagens teóricas que buscam entender e traçar estimativas para o produto nacional, consumo, renda, entre outros indicadores 
de desenvolvimento e atividade econômica, existe em comum, a noção de que as atividades econômicas ocorrem em fluxo, o que fortalece a noção de sistema econômico. Nesta perspectiva, os vínculos existentes entre a unidade de produção rural e as diversas indústrias que fornecem insumos e processam a produção originária da agropecuária, são considerados pelos efeitos multiplicadores da unidade de produção rural. Assim, a compreensão teórica do agronegócio é um diferencial para análise econômica, pois considera a cadeia produtiva como uma unidade de análise, diferentemente dos estudos que buscam entender a economia a partir de uma visão fragmentada.

Essa perspectiva também foi considerada por Santana (1994), em estudo sobre a importância do agronegócio para o desenvolvimento econômico brasileiro, a partir da teoria do crescimento sustentado e da interligação macroeconômica, Neves, Zylbersztajn e Neves (2005), em estudo sobre o potencial do agronegócio, das cadeias e das redes e cooperativas e, Mendes e Padilha Junior (2007) que estudam o agronegócio e posicionam a propriedade rural no elo central da atividade econômica, em visão sistêmica que também agrega os aspectos relacionados ao desenvolvimento econômico.

Deste modo, a busca pelo lucro econômico, razão principal do empreendimento, seja rural ou urbano, empresarial, patronal ou familiar, é o que move os agentes econômicos que integram a cadeia produtiva. Isto explica as estratégias e a busca pela competitividade das empresas e das propriedades rurais, bem como a estrutura concorrencial dos mercados que compõem o agronegócio, pois a concorrência é um processo seletivo característico de toda economia mercantil e, em vista deste, as empresas se posicionam estrategicamente para sobreviver e expandir (POSSAS, 1993). Entretanto, quanto mais bem sucedida for a empresa, maior deverá ser sua participação de mercado e, por consequência, sua capacidade de estabelecer barreiras à entrada de novos concorrentes e de captar os excedentes do produtor rural.

Nesta estrutura, as decisões das empresas que estão posicionadas nos elos a montantes e a jusante do elo de produção da cadeia, tomadas a partir de múltiplos fatores e com o objetivo de elevar sua reprodução do capital via aumento da competitividade, tendem a impactar diretamente a situação econômica dos produtores rurais, o que corrobora os postulados teóricos de Silva (2008), de que os excedentes econômicos do setor agropecuário dependem mais do setor urbano-industrial do que de sua capacidade de aumentar a produtividade dentro da porteira.

\footnotetext{
1) A situação econômica dos produtores rurais depende muito mais de condições externas ao meio do que de condições internas; e 2) Incentivos ao crescimento da produtividade agropecuária, por si só, não são relevantes como estratégia de desenvolvimento econômico e geração de empregos, no longo prazo (SILVA, 2008. p. 302-303).
}

Portanto, a análise da concentração de mercado ao longo da cadeia produtiva da soja e do reflexo desta para os sojicultores requer o resgate dos postulados teóricos que combinam o entendimento sistêmico da atividade econômica com os fundamentos de análise da concorrência e competitividade, 
que podem contribuir para se entender o status quo das relações entre sojicultores, indústria para agricultura e agroindústria.

\section{MATERIAL E MÉTODOS}

Para analisar o poder de mercado nos elos a montante e jusante da produção de soja, utilizar-se-ão métodos de análise qualitativa e quantitativa.

Em seus aspectos essenciais, a pesquisa qualitativa se traduz na escolha de teorias e métodos, em reflexões, no reconhecimento e na análise de diferentes perspectivas dos pesquisadores a respeito de sua pesquisa (FLICK, 2004). Assim, a estrutura de mercado não será reduzida em variável única, mas será estudada em sua complexidade inter e intra-setorial. Para tanto, a análise textual, temática e interpretativa, descrita por Severino (2002) também servirá aos propósitos deste estudo.

Por considerar que a concentração industrial é um dos principais determinantes da concorrência, a mensuração dessa variável fornecerá elementos para a avaliação do nível concorrencial das empresas nos mercados, bem como da dinâmica do processo pelo lado da oferta. Para Kon (1999) e Ferguson e Ferguson (1994), os indicadores utilizados para mensurar a concentração de mercado estão relacionados, principalmente, com a capacidade produtiva, valor e quantidade das vendas. Nessa perspectiva, as variáveis utilizadas para mensurar a concentração nos diversos segmentos que compõem a cadeia produtiva em análise são apresentadas no Quadro 1.

\section{Quadro 1. Variáveis utilizadas para mensurar a concentração de mercado nos segmentos que fornecem insumos e demandam a produção da lavoura de soja no Brasil}

\begin{tabular}{|c|c|c|}
\hline Segmento & Variável Utilizada & Fonte \\
\hline Fertilizantes & Capacidade Instalada de Produção (t/ano) & ANDA (2010) \\
\hline \multirow{3}{*}{ Defensivos } & Montante produzido por empresa (t/ano) & Brasil (2010) \\
\hline & Montante comercializado por empresa (t/ano) & Brasil (2010) \\
\hline & Número de produtos registrados por empresa & AENDA (2011) \\
\hline $\begin{array}{l}\text { Máquinas e } \\
\text { equipamentos }\end{array}$ & $\begin{array}{l}\text { Vendas internas de tratores e colheitadeiras } \\
\text { (un/ano) }\end{array}$ & ANFAVEA (2010) \\
\hline \multirow{4}{*}{ Agroindústria } & & ABIOVE (2011a) \\
\hline & Capacidade Instalada de Produção (t/dia) & (2011a; \\
\hline & Exportações (US\$/ano) & $2012 b)$ \\
\hline & Volume comercializado de soja ( $\mathrm{R} \$ / \mathrm{ano})$ & $\begin{array}{l}\text { Brasil } \\
2007 c)\end{array}$ \\
\hline
\end{tabular}

Fonte: Elaborado pelo autor.

Por fim, entre as medidas de concentração sugeridas por Ferguson e Ferguson (1994) e Kon (1999) serão calculados o Market Share $\left(P_{i j}\right)$ a Relação de Concentração $\left(\mathrm{CR}_{k}\right)$ e o Índice de Herfindahl-Hirschman $(\mathrm{IHH})$. 


\subsection{Market Share}

O Market Share reflete a participação de mercado da firma $i$ na indústria j. É calculado a partir da capacidade de produção da indústria $(\ulcorner)$, ou variável congênere disponível, e elencada na coluna dois do Quadro 1, e da capacidade de produção (ou variável congênere) da i-ésima firma da indústria $i(i=1,2,3$, $\ldots, n)$, expressa por $\mathrm{y}_{i}$, de modo que:

$$
\Gamma_{j}=\sum_{\mathrm{i}=1}^{\mathrm{n}} \gamma_{\mathrm{ij}}
$$

Assim, a participação de mercado da firma individual $\left(\mathrm{P}_{\mathrm{ij}}\right)$ é expressa por um indicador que varia entre zero e 100, em que:

$$
\mathrm{P}_{\mathrm{ij}}=\frac{(100 \times \gamma)_{i j}}{\Gamma_{j}}
$$

O resultado do índice aponta para o percentual de mercado que cada empresa possui. No Brasil, a Lei n. $^{\circ} 8.884 / 1994$ estabelece que o domínio de $20 \%$ do mercado, por uma empresa, é relevante.

\subsection{Relação de Concentração}

A Relação de Concentração $\left(\mathrm{RC}_{k}\right)$ "mede a proporção representada por um número fixo das maiores firmas da indústria, em relação ao total da indústria" (KON, 1999. p.60).

$$
\mathrm{RC}_{\mathrm{k}}=\sum_{\mathrm{i}=1}^{\mathrm{n}} \mathrm{P}_{\mathrm{ij}}
$$

Em que: $n$ e $k=$ número de firmas selecionadas; $P_{i j}=$ market share $=$ participação da firma $i$ no segmento $j$.

$\mathrm{O}$ resultado do $\mathrm{RC}_{\mathrm{k}}$ demonstra o market share das $\mathrm{k}$ maiores empresas, em participação de mercado. Neste caso, um $k=4$ representa a soma das fatias de mercado das quatro maiores empresas e assim sucessivamente.

Para aferir a existência, ou não, de concentração de mercado e definir o nível da mesma, utilizaram-se os critérios estabelecidos por Medeiros e Reis (1999) e Fraga e Medeiros (2005), descritos no Quadro 2. 
Quadro 2. Tipos de mercado segundo $\mathrm{RC}_{4}$

\begin{tabular}{|ll|}
\hline Níveis de Mercados & Razão de Concentração (RC \\
\hline Altamente concentrado & $\mathrm{RC}_{4}>75 \%$ \\
Alta concentração & $65 \%<\mathrm{RC}_{4}<75 \%$ \\
Concentração moderada & $50 \%<\mathrm{RC}_{4}<65 \%$ \\
Baixa concentração & $35 \%<\mathrm{RC}_{4}<50 \%$ \\
Ausência de concentração & $\mathrm{RC}_{4}<35 \%$ \\
Claramente atomístico & $\mathrm{RC}_{4}<2 \%$ \\
\hline
\end{tabular}

Fonte: Medeiros e Reis (1999) e Fraga e Medeiros (2005).

Obs.: Critérios válidos para a análise do $\mathrm{RC}_{4}$ (concentração das quatro maiores empresas).

Uma indústria pode ser classificada como altamente concentrada quando $\circ \mathrm{RC}_{4}$ for superior a $75 \%$. Nestes casos, as quatro (ou menos) empresas tendem a atuar em conluio e comportar-se como um monopolista. Por outro lado, se o índice for inferior a 40\%, a competição entre as empresas tende a ser efetiva (MENDES, 1998).

\section{3. Índice de Herfindahl-Hirschman (IHH)}

O Índice de Herfindahl-Hirschman, terceiro indicador utilizado para mensurar a concentração de mercado, mostra-se especialmente relevante para a pesquisa, uma vez que a fórmula do $\mathrm{IHH}$ permite atribuir ao índice uma interpretação teórica, pois está relacionado ao processo de maximização de lucros pelas empresas (RESENDE; BOFF, 2002).

Em razão das características homogêneas ${ }^{3}$ dos insumos ofertados, pressupõe-se que esses mercados operam em equilíbrio em Cournot, "sob a hipótese de que cada empresa $i$ escolhe as quantidades $q_{i}$ que maximizam seu lucro individual $\pi_{i}\left(q_{1}, q_{2}, \ldots, q_{i}, \ldots q_{n}\right)=q_{i} P\left(\sum_{i=1}^{n} q_{j}\right)-C_{i}\left(q_{i}\right)$, não antecipando qualquer reação dos competidores a uma mudança nas suas quantidades escolhidas" (RESENDE; BOFF, 2002. p.79). Concluem os autores que quanto mais elevado o $\mathrm{HHH}$, mais distante da posição ótima se encontra a posição da indústria. Em função disso, o $\mathrm{IHH}$ é um índice normativo nos Estados Unidos, ou seja, serve de parâmetro para a norma jurídica, no que se refere às análises do direito da concorrência e autorizações de fusões e aquisições.

Em razão disso, as agências antitrustes, em especial as norteamericanas, passaram a utilizar esse indicador, que é calculado a partir da soma dos quadrados da fatia de mercado de cada firma $\left(\mathrm{P}_{\mathrm{i}}\right)$, em relação ao tamanho da indústria $j$ :

\footnotetext{
3 Existem substitutos próximos para a maioria dos insumos agrícolas ofertados pelas empresas. No segmento de fertilizantes, defensivos e máquinas e equipamentos, os produtos comercializados por uma empresa podem ser substituídos pelos bens ofertados por firmas concorrentes. Mesmo um defensivo ofertado em situação de monopólio sobre a concorrência de produtos a base de outras substâncias, mas que geram resultados semelhantes. No segmento de sementes, também é facultado ao produtor rural a escolha, mesmo considerando que as cultivares transgênicas são um quase monopólio (pode-se optar por utilizar cultivares convencionais).
} 


$$
\mathrm{IHH}=\sum_{\mathrm{i}=1}^{\mathrm{n}} \mathrm{P}_{\mathrm{ij}}^{2}
$$

Pode variar de 0 a 10.000, com os extremos representando concorrência perfeita e monopólio. As empresas com maior market share participam com maior peso na formação do índice, pois market share mais elevado, atribui-se maior peso às empresas maiores, de modo que o índice proporciona informações sobre a dispersão do tamanho da firma na indústria (MENDES, 1998; RESENDE; BOFF, 2002). Desse modo, quando existe uniformidade entre as firmas de uma indústria, ou quando o número de empresas se eleva, o IHH diminui. Nessa perspectiva, o Horizontal Mergers Guidelines (UNITED STATES OF AMERICA, 2010) assume três faixas para balizar a tomada de decisão em processos de fusão empresarial:

a) $\mathrm{IHH}<1.500$ : mercado não concentrado;

b) Entre $1.500 \leq \mathrm{HH} \leq 2.500$ : mercado com nível moderado de concentração. Neste caso a autorização de fusões pode acarretar problemas à concorrência, principalmente se o $\mathrm{IHH}$ aumentar acima de 100 pontos, em relação ao índice pré-fusão;

c) $\mathrm{IHH}>$ 2.500: mercado altamente concentrado. Nesta situação, as fusões podem causar significativos problemas de concorrência, sobretudo, se o aumento do IHH estiver entre 100 e 200 pontos, quando comparados ao índice inicial. No caso de aumento superior a 200 pontos, presume-se que o poder de mercado será ainda mais reforçado.

Mesmo considerando o caráter arbitral das faixas definidas, neste trabalho utilizaram-se os intervalos definidos pela Comissão Federal de Comércio e Departamento de Justiça dos Estados Unidos, por ser uma classificação mais recente e utilizada para mensurar a concentração de mercado nos Estados Unidos da América, que mais evoluiu na questão até o momento.

\section{RESULTADOS E DISCUSSÕES}

A presente seção apresenta os resultados e análise de indicadores de concentração para os segmentos situados à montante e jusante da lavoura de soja. Quanto maior o poder de mercado auferido pela firma, mais exitosa foi sua estratégia.

Por considerar que a análise de concentração do segmento de sementes transgênicas e convencionais já foi analisada por Costa e Santanta (2013), o presente estudo restringir-se-á a analisar os segmento de fertilizantes, defensivos, máquinas e de processamento do grão. 


\subsection{Segmento de Produção de Fertilizantes}

O fertilizante ofertado aos produtores se constitui através de mistura de formulação de NPK (nitrogênio, fósforo e potássio) e é resultante de uma sucessão de transformação em cadeia que inicia na extração mineral de matérias-primas (gás natural, petróleo, resíduos pesados, nafta, enxofre natural piritas, rocha fosfática "in situ" e rocha potássica).

A partir das matérias-primas, são constituídas a amônia, enxofre, rocha fosfática e cloreto de potássio que, em processo industrial, são utilizados para a produção dos intermediários para fertilizantes e, posteriormente, em produtos finais: cloreto de potássio, fosfato diamônio DAP, fosfato monoamônio MAP, nitrato de amônio, sulfato de amônio, superfosfato simples (pó), superfosfato triplo (pó), ureia, termofosfato, rocha parcialmente acidulada e nitrocálcio (Figura 1).

Figura 1. Cadeia Produtiva dos Fertilizantes

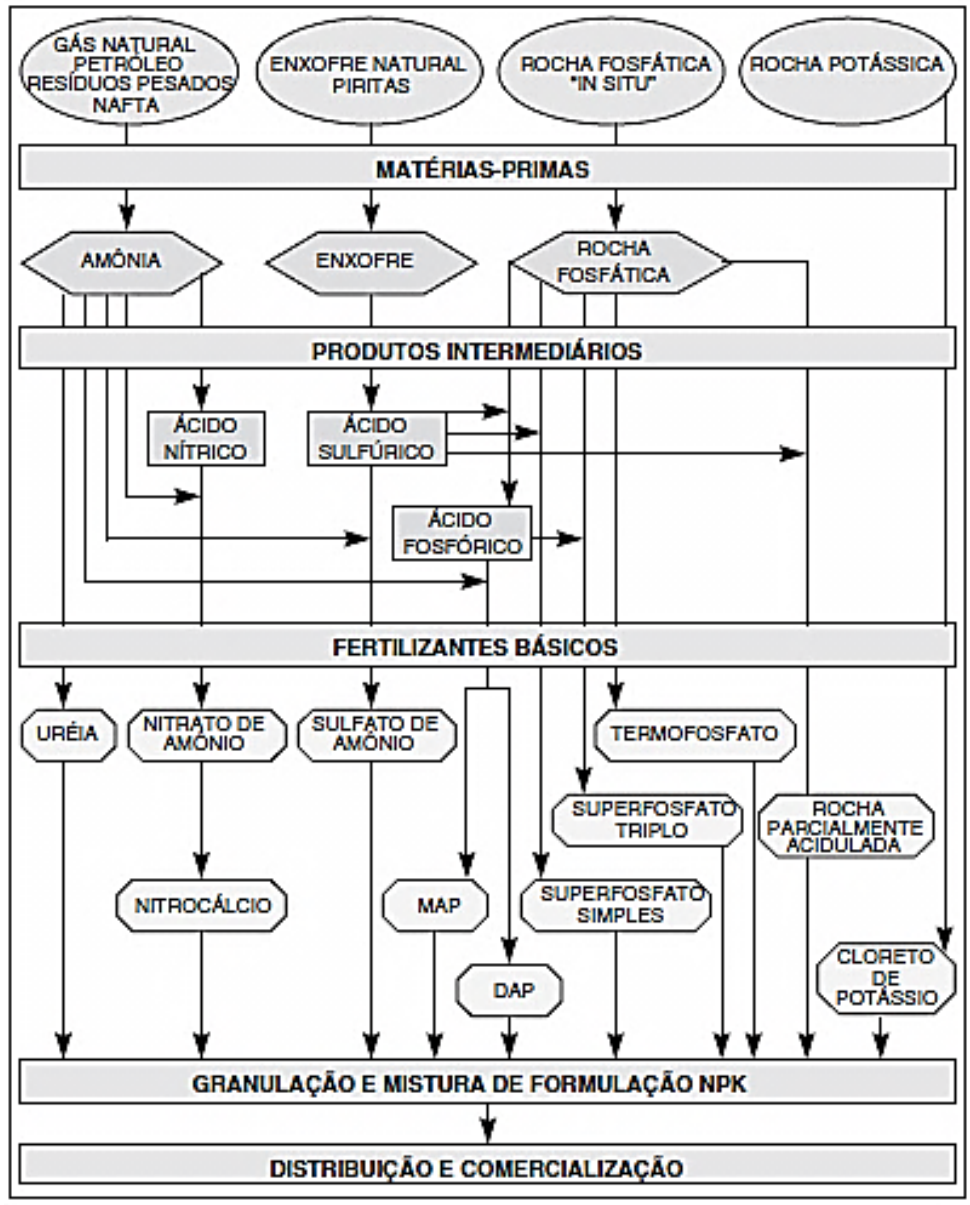

Fonte: Dias e Fernandes (2006, p. 100).

O Brasil consome cerca de $5,7 \%$ do total produzido no mundo e se constitui como o quarto maior demandante internacional (2009), ficando atrás de China (31,0\%), Índia (16,2\%) e Estados Unidos (11,3\%) (ANDA, 2010; IFA, 2012). Internamente, a soja é a cultura que mais demanda NPK, sendo 
responsável por aproximadamente $35 \%$ dos 22.471 mil toneladas de produtos entregues às propriedades rurais, em 2009 (ANDA, 2010).

Considerando que $56,7 \%$ dos fertilizantes ofertados no mercado interno são importados (Figura 2) (ANDA, 2010; IPEAData, 2012), o governo brasileiro está desenvolvendo o Plano Nacional de Fertilizantes, cujo objetivo continua sendo reduzir a dependência brasileira do mercado externo. Neste, estão previstos estímulos à busca por novas jazidas, exploração das já avaliadas e conhecidas, além do aumento na produção de fertilizantes orgânicos e organominerais através da instalação de plantas industriais para processar os dejetos de suínos e de frango nas regiões onde a produção é intensiva. Por outro lado, as recentes reservas de gás e petróleo, descobertas no Pré-Sal, resultarão em redução da dependência nacional por matéria-prima estrangeira (BRASIL, 2011a; 2012c).

Figura 2. Produção e importação de fertilizantes no Brasil: 1998 a 2009

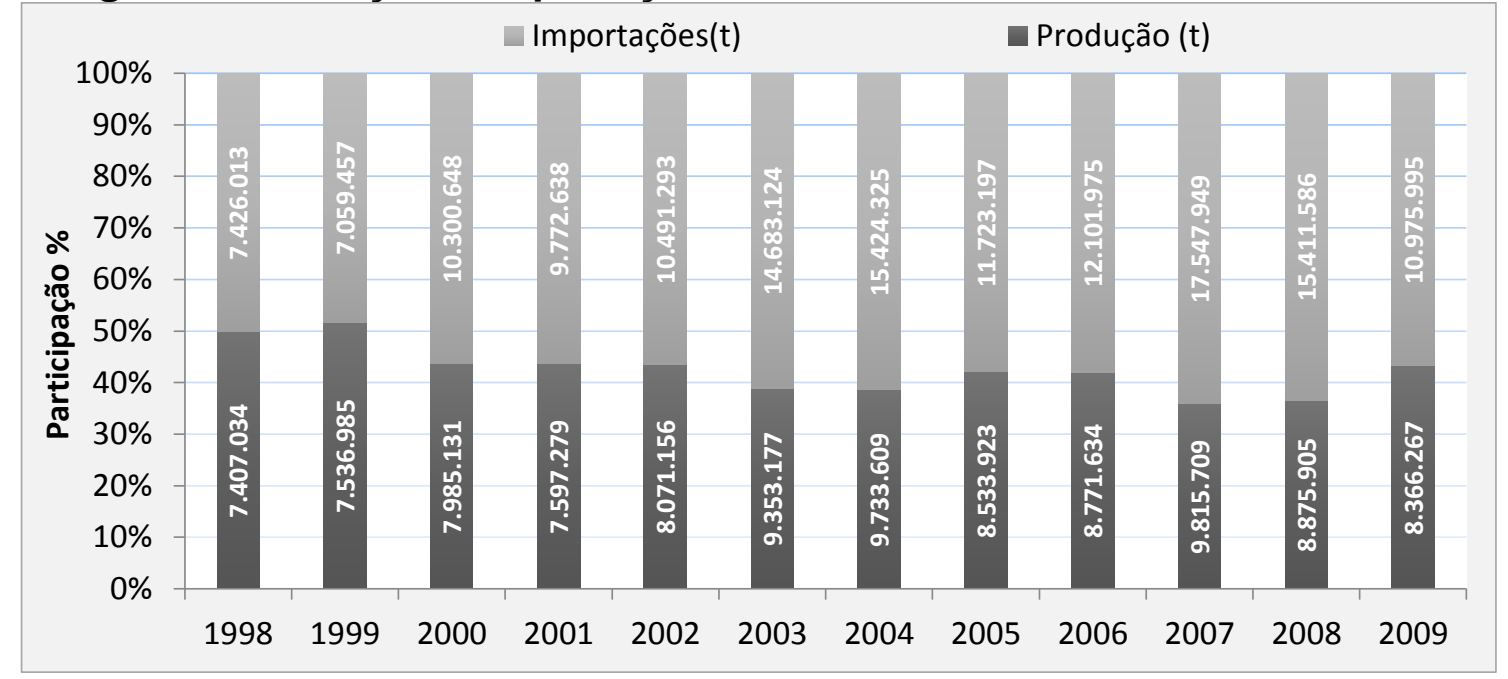

Fonte: ANDA (2010); IPEAData (2012).

Entre as principais empresas do setor, destacam-se: Bunge Fertilizantes S.A., com market share de 31,1\%; Mosaic Fertilizantes Ltda., com 14,7\%; Fósfértil S.A., com 13,6\%; Fertilizantes Heringer S.A., com 12,7\%, e; Yara Brasil Fertilizantes S/A, com 12\% (ABIQUIM, 2008). Nesta conjuntura, a Relação de Concentração das quatro maiores empresas $\left(R_{4}\right)$ equivale a $72,1 \%$, o que indica alta concentração, segundo os critérios estabelecidos por Medeiros e Reis (1999) e Fraga e Medeiros (2005). Além disso, ambas as empresas posicionaram-se estrategicamente ao longo da cadeia produtiva de fertilizantes, também reproduzindo sua estrutura de poder nos segmentos de matérias-primas para fertilizantes e intermediários para fertilizantes, o que corrobora a estratégia de hierarquização de filière apresentada por Mendes, Figueiredo e Michels (2008). 
4.1.1. Mercado de Produção de Matérias-Primas para Fertilizantes:

As matérias-primas utilizadas para a produção de intermediários para fertilizantes são ácido fosfórico (P2O5), amônia anidra, rocha fosfática e enxofre. Dessas, o enxofre não está presente no setor mineral brasileiro, de modo que é importado integralmente pelas empresas do setor. Em 2009, as importações de enxofre (NCM 2503.10.10) e ácido sulfúrico (NCM 2807.00.10) somaram de 1.507 .592 e 336.808 toneladas, respectivamente (ANDA, 2010; BRASIL, 2012c), oque corrobora a importância do comércio exterior para a fabricação de intermediários para fertilizantes (FERNANDES; GUIMARÃES; MATHEUS, 2009).

A possibilidade de importação de matérias-primas para fertilizantes poderia se constituir, enquanto limitação do poder de mercado das empresas domésticas que atuam no segmento de produção de matéria-prima, uma vez que as firmas que atuam no segmento de intermediários podem adquirir seus insumos no mercado externo. Entretanto, as empresas do setor de produção de matéria-prima para fertilizantes constituem a base do oligopólio do setor de intermediários para fertilizantes. Portanto, atribui-se a maior fração da importação de matéria-prima para fertilizantes à elas.

Em 2009, a capacidade instalada situou-se no patamar de 14,44 bilhões de toneladas, dos quais, $86 \%$ estão concentrados em plantas industriais da Fosfértil S.A. e Bunge Fertilizantes S.A. (adquiridas pela Vale Fertilizantes S.A., em 2010) e Copebrás. Minas Gerais, São Paulo e Goiás reúnem $87 \%$ das plantas industriais, demonstrando que o agrupamento industrial também se replica em âmbito geográfico (Figuras 3a e 3b) (ANDA, 2010).

Figura 3. Capacidade Instalada de Produção de matérias-primas para fertilizantes (t/ano): 2009

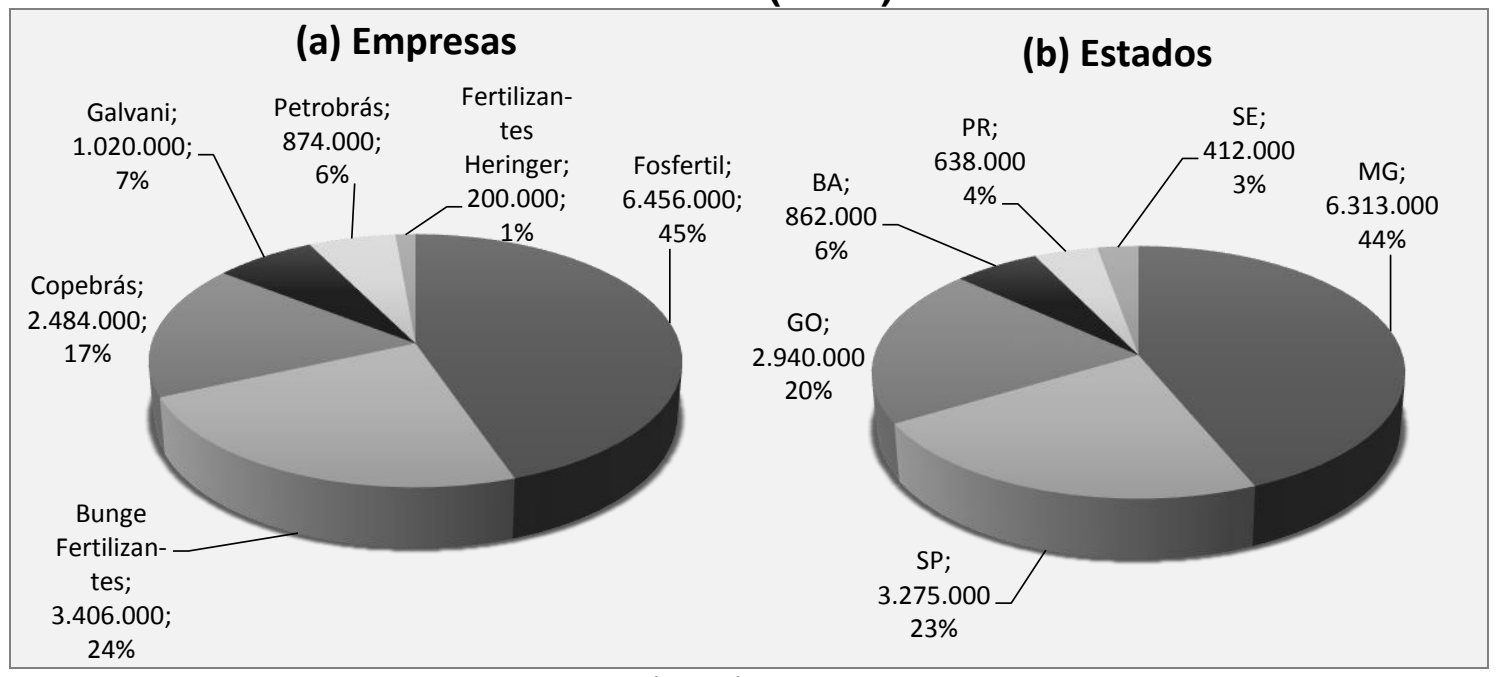

Fonte: Elaboração com base em ANDA (2010). 
De acordo com os critérios de análise do índice $\mathrm{RC}_{4}$, o mercado está altamente concentrado. Neste sentido, destacam-se: a) a representatividade da empresa Fosfértil S.A., pois responde por $40 \%$ da capacidade instalada de produção de ácido fosfórico $\left(\mathrm{P}_{2} \mathrm{O}_{5}\right), 43 \%$ de amônia anidra e $49 \%$ da rocha fosfática; b) a importância da Bunge Fertilizantes S.A., que responde por $28 \%$ da capacidade instalada de ácido fosfórico $\left(\mathrm{P}_{2} \mathrm{O}_{5}\right)$ e $25 \%$ de rocha fosfática, e; c) a participação de mercado do Grupo Galvani, equivalente a $9 \%$ da capacidade de produção do ácido fosfático $\left(\mathrm{P}_{2} \mathrm{O}_{5}\right)$ e $7 \%$ da rocha fosfática (Tabela 1).

Tabela 1. Capacidade Instalada de Produção (yi) (mil t/ano), Market Share (Pij) e Índice de Herfindahl-Hirschman (IHH) para o setor de produção de Matérias-Primas para Fertilizantes: 2009

\begin{tabular}{|c|c|c|c|c|c|c|c|c|c|}
\hline & \multicolumn{3}{|c|}{ Ácido Fosfórico (P2O5) } & \multicolumn{3}{|c|}{ Amônia Anidra } & \multicolumn{3}{|c|}{ Rocha Fosfática } \\
\hline & $Y_{i}$ & $\mathbf{P}_{\mathrm{ij}}$ & IHH & $Y_{i}$ & $\mathbf{P}_{\mathrm{ij}}$ & IHH & $Y_{i}$ & $\mathbf{P}_{\mathrm{ij}}$ & IHH \\
\hline Galvani & 540 & 9 & & - & - & - & 480 & 7 & \\
\hline Copebrás & 1.184 & 20 & & - & - & - & 1.300 & 19 & \\
\hline Fosfertil & 2.384 & 40 & & 647 & 43 & 1.809 & 3.425 & 49 & \\
\hline $\begin{array}{l}\text { Fertilizantes } \\
\text { Heringer }\end{array}$ & 200 & 3 & & - & - & - & - & - & \\
\hline $\begin{array}{l}\text { Bunge Ferti- } \\
\text { lizantes S.A. }\end{array}$ & 1.691 & 28 & & - & - & - & 1.715 & 25 & \\
\hline Petrobrás S.A. & - & - & & 874 & 57 & 3.302 & - & - & \\
\hline Total & 5.999 & 100 & 2.856 & 1.521 & 100 & 5.111 & 6.920 & 100 & 3.465 \\
\hline
\end{tabular}

Considerando os parâmetros do Horizontal Mergers Guidelines (UNITED STATES OF AMERICA, 2010), o mercado de todas as matérias-primas para fertilizantes no Brasil é altamente concentrado, uma vez que todos os valores de $\mathrm{IHH}$ situaram-se acima de 2.500 pontos, chegando a 2.856, 5.511 e 3.465 para os mercados de ácido fosfórico $\left(\mathrm{P}_{2} \mathrm{O}_{5}\right)$, amônia anidra e rocha fosfática, respectivamente. Uma das explicações para o fato é a magnitude do capital envolvido nas operações e, sobretudo, a restrição ao acesso dos recursos naturais.

As características do produto em análise não permitem livre entrada de concorrentes, uma vez que a atividade exige significativa alavancagem de capital inicial, descobrimento de novas jazidas e concessão de lavra pelo Departamento Nacional de Produção Mineral (DNPM). Também, as eficiências das empresas do setor, bem como a qualidade dos produtos, são semelhantes e os substitutos próximos (fertilizantes orgânicos e organominerais) não são produzidos em escala suficiente para atender a demanda da agricultura nacional (BRASIL, 2011a).

Portanto, o seleto grupo de empresas que integra a indústria de matérias-primas para fertilizantes possui capacidade de controlar o preço de venda do produto e a manifestação do poder de mercado verifica-se, justamente, em função disso. Em muitos casos, a manipulação de preços é facilitada, pois as relações de compra e venda entre as distintas indústrias acontecem por unidades das mesmas empresas. Desse modo, o mercado 
externo não compete com o oligopólio do setor de produção interno, o que aumenta o poder de mercado das empresas oligopolistas residentes no Brasil.

\subsubsection{Mercado de Produção de Intermediários para Fertilizantes}

O segmento de intermediários para fertilizantes contempla os mercados de cloreto de potássio, fosfato diamônio DAP, fosfato monoamônio MAP, nitrato de amônio, superfosfato simples (Pó), superfosfato triplo (Pó), termofosfato e ureia. Nesse, observa-se que cinco empresas e quatro estados respondem por $70 \%$ e $71 \%$ da capacidade de produção (Figura 4a e 4b).

Figura 4. Capacidade Instalada de Produção de Fertilizantes - produtos intermediários (t/ano): 2009

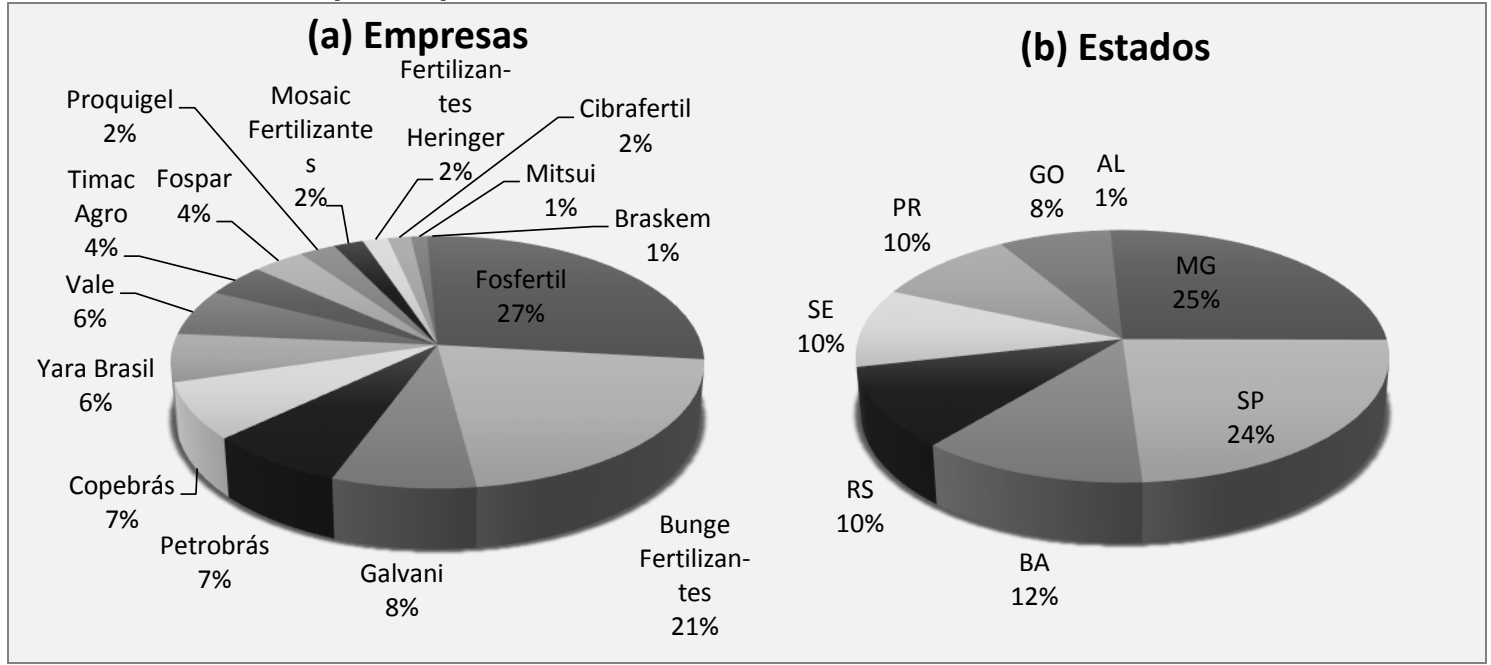

Fonte: Elaboração com base em ANDA (2010).

Entre as empresas com maior market share, destacam-se Fostértil S.A., Bunge Fertilizantes S.A., Galvani, Petrobrás e Copebrás. O poder de mercado de cada empresa varia de acordo com o intermediário comercializado. Observa-se que: a) no mercado de superfosfato simples (pó), Bunge Fertilizantes S.A. e Fosfértil S.A. são as que possuem maior poder de mercado; b) no mercado de fosfato diamônio a empresa Fosfértil S.A. é monopolista e; c) no mercado de superfosfato triplo (pó), também a Fosfértil possui $72 \%$ do market share (Tabela 2). 
Tabela 2. Concentração de Mercado no segmento de produção de Intermediários para Fertilizantes no Brasil: 2009.

\begin{tabular}{|c|c|c|c|c|c|c|c|c|c|}
\hline Empresa & $\begin{array}{c}\text { Superfos } \\
\text {-fato } \\
\text { Simples } \\
\text { (pó) }\end{array}$ & $\begin{array}{l}\text { Fosfato } \\
\text { Diamôn } \\
\text { io DAP }\end{array}$ & $\begin{array}{c}\text { Super- } \\
\text { fosfato } \\
\text { Triplo } \\
\text { (Pó) }\end{array}$ & $\begin{array}{c}\text { Nitrato } \\
\text { de } \\
\text { Amôni } \\
0 \\
\end{array}$ & $\begin{array}{c}\text { Sulfato } \\
\text { de } \\
\text { Amônio }\end{array}$ & $\begin{array}{l}\text { Fosfat } \\
\text { o } \\
\text { Mono- } \\
\text { amôni } \\
\text { o MAP }\end{array}$ & $\begin{array}{l}\text { Termo- } \\
\text { fosfato }\end{array}$ & Ureia & $\begin{array}{c}\text { Cloreto } \\
\text { de } \\
\text { Potássi } \\
0\end{array}$ \\
\hline $\begin{array}{l}\text { Bunge Fertili- } \\
\text { zantes S.A.* }\end{array}$ & $35 \%$ & - & $8 \%$ & - & - & - & - & - & - \\
\hline Braskem & - & - & - & - & $19 \%$ & - & - & - & - \\
\hline Cibrafertil & $3 \%$ & - & - & - & $12 \%$ & - & - & - & - \\
\hline Copebrás* & $10 \%$ & - & $8 \%$ & - & - & $11 \%$ & - & - & - \\
\hline $\begin{array}{l}\text { Fertilizantes } \\
\text { Heringer S.A.* }\end{array}$ & $3 \%$ & - & - & - & - & - & - & - & - \\
\hline $\begin{array}{l}\text { Fertilizantes } \\
\text { Mitsui S.A. }\end{array}$ & - & - & - & - & - & - & $100 \%$ & - & - \\
\hline $\begin{array}{l}\text { Fosfértil } \\
\text { S.A.* }\end{array}$ & $9 \%$ & $100 \%$ & $72 \%$ & $100 \%$ & - & $89 \%$ & - & $37 \%$ & - \\
\hline Fospar & $6 \%$ & - & - & - & - & - & - & - & - \\
\hline Galvani* & $13 \%$ & - & - & - & - & - & - & - & - \\
\hline $\begin{array}{l}\text { Mosaic } \\
\text { Fertilizantes }\end{array}$ & $4 \%$ & - & - & - & - & - & - & - & - \\
\hline $\begin{array}{l}\text { Petrobrás } \\
\text { S.A.* }\end{array}$ & - & - & - & - & - & - & - & $63 \%$ & - \\
\hline Proquigel & & - & - & - & $69 \%$ & - & - & - & - \\
\hline Timac Agro & $7 \%$ & - & $5 \%$ & - & - & - & - & - & - \\
\hline $\begin{array}{l}\text { Vale Fertili- } \\
\text { zantes S.A. }\end{array}$ & - & - & - & - & - & - & - & - & $100 \%$ \\
\hline Yara Brasil & $10 \%$ & - & 7 & - & - & - & - & & - \\
\hline $\mathrm{RC}_{4}$ & $68 \%$ & $100 \%$ & $100 \%$ & $100 \%$ & $100 \%$ & $100 \%$ & $100 \%$ & $100 \%$ & $100 \%$ \\
\hline $\mathrm{IHH}$ & 1.186 & 10.000 & 5.425 & $\begin{array}{c}10.00 \\
0\end{array}$ & 5.296 & 8.113 & 10.000 & 5.319 & 10.000 \\
\hline $\begin{array}{l}\text { Cap. Inst. (mil } \\
\text { t/ano) }\end{array}$ & 8.149 & 8 & 1.086 & 406 & 520 & 1.422 & 160 & 1.686 & 850 \\
\hline
\end{tabular}

Em função disso, a concentração, mensurada pelo $\mathrm{IHH}$, aponta monopólio para os mercados de termofosfato, nitrato de amônio, DAP e cloreto de potássio. Também classifica como altamente concentrado os mercados de MAP, superfosfato triplo (pó), ureia e sulfato de amônio. Apenas o mercado de superfosfato simples é considerado um mercado com níveis moderados de concentração (Tabela 6). Já, quando analisado sob a óptica do $\mathrm{RC}_{4}$, todos os mercados estão altamente concentrados, exceto o de superfosfato simples (pó), que se apresenta em um nível inferior de concentração, também elevado.

Os elevados níveis de concentração e a integração vertical (as mesmas empresas estão presentes na produção e importação de matéria-prima para fertilizantes e intermediários para fertilizantes) posicionam os sojicultores como tomadores de preços 
de que:

Os resultados encontrados refletem a percepção de Brasil (2011a. p. 12)

\begin{abstract}
"A estrutura de concorrência do setor de fertilizantes no Brasil é caracterizada, como na maioria dos países, pela alta concentração e pela integração vertical, pois a produção exige elevados custos iniciais em investimentos, é intensiva em capital e envolve grandes escalas de produção".
\end{abstract}

Também confirmam as conclusões de Fernandes, Guimarães e Matheus (2009), de que o mercado encontra-se concentrado horizontal e verticalmente, uma vez que as empresas dominantes no segmento de intermediário para fertilizantes são, na maioria, as mesmas do setor de matéria-prima para fertilizantes.

Neste contexto, observa-se que, para garantir o sucesso empresarial, as empresas se posicionaram estrategicamente ao longo da cadeia produtiva de fertilizantes, o que corrobora a análise de filière, na qual os autores Bandt (1982; 1988), Dufour e Torre (1985), Carvalho Júnior (1995) e Mendes, Figueiredo e Michels (2008) destacam que o domínio de segmentos estratégicos permite a integração dos processos, a consolidação da posição dominante e a criação de barreiras à entrada de novos concorrentes. Igualmente, a atuação das empresas dominantes ratifica os postulados de Porter (1996), uma vez que, além da eficiência operacional, a estratégia adotada busca consolidar a vantagem competitiva através do planejamento e da integração das atividades empresariais.

\title{
4.1.3. Mercado de Granulação e Mistura de NPK
}

Esse segmento reúne as empresas responsáveis por fazer a mistura dos produtos intermediários e formular os produtos finais, distribuídos aos produtores rurais. Em geral, o alcance das empresas é regional, mas também se observa a presença de grandes empresas como Fertilizantes Heringer S.A., Bunge Fertilizantes S.A. e Yara, porém, com poder de mercado reduzido, no segmento (FERNANDES; GUIMARÃES; MATHEUS, 2009).

Essas empresas operam entre um oligopólio, que fornece insumos, e um mercado concorrencial, que demanda seus produtos. Assim, mesmo em condições de alta concorrência, a fixação de preços está limitada pelo custo dos intermediários para fertilizantes, estabelecido em condições de oligopólio. Dessa forma, mesmo que a firma do segmento de granulação e mistura opere com preços próximos ao custo marginal, estará replicando o poder de mercado das corporações que as precedem.

Considerando que a curva de demanda por fertilizantes mostrou-se inelástica a apreço nas últimas décadas (NICOLELLA; DRAGONE; BACHA, 2005) e que não existem substitutos próximos em quantidade e qualidade suficientes para atender a todos os produtores, a possível adoção de acordos para aumentar preços, tende a resultar em apropriação de renda do produtor rural e maximização de lucros das empresas. 


\subsection{Segmento de Defensivos Agrícolas}

Na medida em que a produção de alimentos se intensificou e passou a ocupar áreas maiores e homogêneas, o manejo de insetos e pragas passou a ser, juntamente com a fertilização do solo, um dos responsáveis pelos índices de produtividade. Os produtos químicos se consolidaram como a base de proteção da lavoura e passaram a ser demandados em função do efeito gerado sobre os inimigos naturais, de seu custo monetário e do benefício da aplicação, em termos de aumento ou manutenção da produtividade esperada.

A indústria de defensivos agrícolas é um subsetor da indústria química e, nas últimas décadas, se caracterizou pelos sucessivos avanços tecnológicos, sejam na química, biotecnologia ou nanotecnologia. Esse processo é resultante dos elevados investimentos nas áreas de PD\&I, sobretudo das empresas privadas, e das sucessivas fusões e aquisições viabilizadas por empresas do segmento. $O$ processo de concentração é explicado pela estratégia adotada para redução de riscos e incertezas no mercado de agrotóxicos, uma vez que o lançamento de um produto inovador pode inviabilizar uma linha completa de produtos. Por outro lado, esse comportamento culminou no aumento do poder econômico das empresas, principalmente as líderes.

Ao adquirirem firmas com competência na área de biotecnologia, as líderes do segmento de defensivos ampliam sua base tecnológica, diversificam seu processo produtivo, aumentam sua competitividade e ampliam participação no mercado (GONÇALVES; LEMOS, 2011. p. 2).

Em geral, observa-se a existência de três categorias de empresas no setor: líderes, seguidoras e emergentes. As líderes são caracterizadas pelos investimentos e inovações em produtos e processos e pela propriedade intelectual do descobrimento de novas moléculas químicas, o que lhes garante o monopólio para determinadas substâncias (TERRA, 2008; GONÇALVES; LEMOS, 2011).

O cenário atual mostra que $58,33 \%$ dos 144 ingredientes ativos (espalhantes adesivo/adjuvante, protetores, feromônios e aleloquímicos e produtos biológicos) utilizados como defensivos, na lavoura de soja, possuem apenas um ofertante, não necessariamente a mesma empresa, enquanto que $13,19 \%$ e $28,47 \%$ são ofertados por duas empresas e três ou mais empresas (AENDA, 2011).

Após 20 anos de exclusividade, a proteção de patentes expira (Art. 40 da Lei 9.279 , de 14 de maio de 1996) e o princípio ativo passa a ser de domínio público. A partir de então, a imitação e produção de genéricos faz com que os preços sejam reduzidos. Como exemplo é possível citar o herbicida sistêmico não seletivo glifosato, hoje disponível para o mercado na forma de 53 produtos, ofertados por 22 empresas, entre as quais a Monsanto do Brasil Ltda., Nortox S.A., Nufarm Ltda., Milenia Agrociências S.A., DowAgrociences, Cheminova Brasil Ltda., Atanor do Brasil Ltda., o que demonstra que mesmo forte nas especialidades, as principais empresas do setor também atuam nos genéricos. 
Nos casos em que o ingrediente ativo é muito utilizado, a exemplo do glifosato, que corresponde a $30 \%$ dos ingredientes ativos consumidos no Brasil (OLIVEIRA, 2011), a estratégia utilizada pelas empresas dominantes é a diversificação de produtos. A Monsanto, por exemplo, possui diversos produtos à base de glifosato: Roundup Original, Roundup Ready, Roundup Transorb, Roundup Ultra entre outros. Também, as empresas dominantes investem em propaganda e marketing e no relacionamento direto com os produtores rurais, via representantes regionais, de modo que é comum a organização de "dias de campo" para mostrar a eficácia dos produtos, o patrocínio de viagens nacionais e internacionais para os grandes produtores e formadores de opinião, a organização de eventos festivos e a distribuição de souvenires (bonés, facas para churrasco, canetas, etc.) personalizados com a marca da empresa.

Segundo estimativas (BRASIL, 2010), em 2009, foram comercializados 800,19 mil toneladas de defensivos agrícolas no mercado brasileiro. As 10 maiores empresas responderam por $77,7 \%$ da fatia de mercado, destacandose a posição dominante das firmas Syngenta Seeds Ltda., Milenia Agrociencias S.A., Monsanto do Brasil Ltda. e Nufarm Ltda.

Mesmo classificado como de concentração moderada, as seis empresas com maior número de produtos registrados para o manejo da lavoura de soja no Brasil, agregam $50 \%$ dos produtos disponíveis (Tabela 5 ).

Tabela 3. Número de defensivos agrícolas registrados para os tratos culturais da soja no Brasil: 2011

\begin{tabular}{lllll}
\hline $\boldsymbol{k}$ & Empresa Responsável & $\begin{array}{l}\text { No } \\
\text { Registros }\end{array}$ & $\begin{array}{c}\text { de } \\
\text { Reg }\end{array}$ & $\mathbf{R C}_{\mathbf{k}}$ \\
\hline 1 & Bayer CropScience Ltda. & 66 & $12,69 \%$ & $12,69 \%$ \\
2 & Basf Poliuretanos Ltda. & 49 & $9,42 \%$ & $22,12 \%$ \\
3 & Milenia Agrociências S.A. & 46 & $8,85 \%$ & $30,96 \%$ \\
4 & Syngenta Seeds Ltda. & 41 & $7,88 \%$ & $38,85 \%$ \\
5 & Cheminova Brasil Ltda. & 31 & $5,96 \%$ & $44,81 \%$ \\
6 & FMC Agricultural Products & 29 & $5,58 \%$ & $50,38 \%$ \\
7 & Dow AgroSciences Ltda. & 23 & $4,42 \%$ & $54,81 \%$ \\
8 & Sumitomo Corporation do Brasil S.A. & 19 & $3,65 \%$ & $58,46 \%$ \\
9 & Agripec Química e Farmacêutica S.A. & 18 & $3,46 \%$ & $61,92 \%$ \\
10 & Nortox S.A. & 17 & $3,27 \%$ & $65,19 \%$ \\
11 & DuPont do Brasil S/A. & 15 & $2,88 \%$ & $68,08 \%$ \\
12 & Arysta LifeScience & 14 & $2,69 \%$ & $70,77 \%$ \\
13 & Sipcam Isagro & 14 & $2,69 \%$ & $73,46 \%$ \\
14 & Monsanto do Brasil Ltda. & 11 & $2,12 \%$ & $75,58 \%$ \\
\hline & Outros & 127 & $24,42 \%$ & $100,00 \%$ \\
\hline & TOTAL & 520 & $100 \%$ & \\
\hline
\end{tabular}

Fonte: Elaboração própria, com base em AENDA (2011).

Observa-se, portanto, que as empresas líderes de agroquímicos no Brasil são filiais de grandes corporações internacionais que competem no segmento de produtos de alto valor agregado, em função de investimentos em P,D \& I de suas matrizes, cujos retornos são apropriados na forma de patentes.

No âmbito internacional, a estrutura é semelhante a do mercado interno, pois Bayer CropScience Ltda., Syngenta Seeds Ltda, DuPont S/A., Basf S.A. e Dow Agro Sciences aumentaram suas participações de mercado e se 
consolidaram como as maiores do setor, conforme é possível observar em Brasil (2010).

Este mercado é composto por firmas oligopolistas que, em geral, utilizam estratégias agressivas, pois definem metas aos vendedores de varejo e contratam engenheiros agrônomos como representantes comerciais, o que define maior capacidade de persuasão e maior volume de vendas, principalmente quando existe risco de ataques biológicos, inerentes aos cultivos homogêneos.

Por outro lado, as necessidades de proteção da soja tornam essencial a aplicação de defensivos, principalmente nos momentos de ataques de insetos, fungos, ácaros e ervas concorrentes. Em função disso, a concorrência no setor, inexistente para vários produtos, parece ser a única aliada do produtor na hora da aquisição dos defensivos.

\subsection{Segmento de Máquinas Agrícolas}

Assim como nos segmentos de fertilizantes e defensivos, a indústria de tratores e colheitadeiras (combines) é caracterizada pelas sucessivas incorporações de novas tecnologias em processos e produtos. Os tratores, que antes possuíam 65 cavalos de potência (cv), a exemplo do Massey Ferguson modelo 65, hoje chegam a 370cv (Massey Ferguson Série MF 8600) e são equipados com interface que permite controlar todas as funções de agricultura de precisão (COSTA, 2008).

Entende-se por agricultura de precisão, a adoção de técnicas e procedimentos que visam customizar a aplicação de insumos e mapear a produtividade. Isto é realizado a partir de máquinas com equipamentos gerenciados por softwares e conectados aos satélites, que utilizam o sistema de posicionamento global (GPS) e matrizes de dados como parâmetros para definir a quantidade e tipo de insumo aplicado, no momento do plantio e tratos culturais, bem como, para coletar informações na hora da colheita.

Em geral, as maiores colheitadeiras podem alcançar até $431 \mathrm{cv}$ e possuir plataformas de corte flexíveis que chegam a 40 pés (12,2 metros de largura), como é o caso da colheitadeira 9770 STS da John Deere, o que garante alto nível de produtividade operacional. O mesmo ocorre com plantadeiras, que distribuem de forma uniforme sementes, a exemplo da plantadeira DB 90 da John Deere. Os pulverizadores, completamente automatizados, atingem velocidades de pulverização de até $32,5 \mathrm{~km} / \mathrm{h}$, mantendo alta qualidade de aplicação (pulverizador MF 9030 da Massey Ferguson e New Holland SP3500).

Combinando os avanços no setor de fertilizantes, defensivos e máquinas agrícolas, o tempo destinado para os tratos culturais foi significativamente reduzido e a produtividade/ha aumentou. Assim, a produtividade por hora/trabalho, na lavoura de soja, elevou-se de 1,15 sacas, em 1980, para 19,83 sacas em 2005 (COSTA, 2008). Por outro lado, o grau de submissão da produção agrícola ao setor industrial aumentou e, por consequência, o poder de mercado das empresas oligopolistas que fornecem insumos para a lavoura também (GOODMAN, SORJ, WILKINSON, 1989). 
No segmento de tratores de rodas, poucas firmas dominam parcela significativa do mercado: Valtra do Brasil Ltda., John Deere Brasil Ltda., CNH Latin America Ltda. (proprietária das marcas New Holland e Case) e AGCO do Brasil Comércio e Indústria Ltda. (proprietária da marca Massey Ferguson) concentram 96,28\% do market share das vendas internas. Mesma situação é verificada no comércio de colheitadeiras, em que John Deere Brasil Ltda., CNH Latin America Ltda. e AGCO do Brasil Comércio e Indústria Ltda. respondem por $96,82 \%$ da fatia de mercado.

Considerando os critérios estabelecidos pelo Horizontal Mergers Guidelines (UNITED STATES OF AMERICA, 2010) para análise do IHH, afirma-se que o mercado de colheitadeiras é altamente concentrado e o mercado de tratores está em nível moderado de concentração. Por outro lado, observa-se que, entre 1960 e 2009, o $\mathrm{IHH}$ do mercado de tratores de rodas decresceu a uma taxa geométrica de $-1,58 \%$ ao ano, enquanto que entre 1976 e 2009, o IHH do mercado de colheitadeiras cresceu a uma taxa geométrica de $0,30 \%$ ao ano, o que demonstra a inexistência de mudanças significativas no poder de mercado das empresas nas últimas três décadas (Figura 9).

Figura 5. IHH para o segmento colheitadeiras e tratores de rodas no Brasil - Vendas Internas: 1976 - 2009

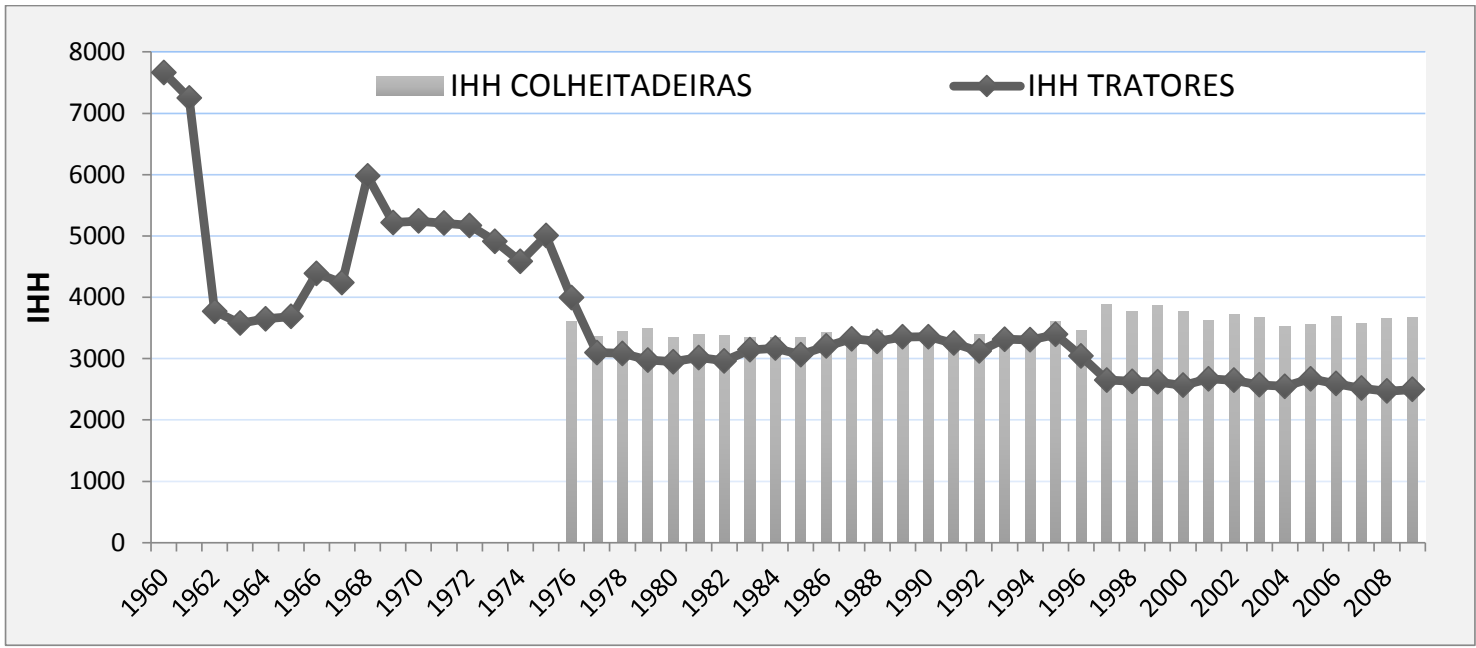

Fonte: Elaboração própria, com base em Anfavea (2010).

A teoria schumpeteriana da concorrência explica a atual conjuntura, uma vez que a estratégia adotada pelas empresas está pautada na obtenção de vantagens competitivas e na busca pela diferenciação. Assim, o atual estágio de avanço tecnológico do segmento pode ser explicado pela construção, ao longo dos anos, de um ambiente propício à competitividade. Adicionalmente, a estratégia fundamentada nas inovações tecnológicas é considerada por Porter (1992; 1999) uma eficiente alternativa para manter e construir posições competitivas sustentáveis.

No âmbito das políticas de crédito, que afetam diretamente as vendas do setor, observa-se que o governo federal, através da oferta de crédito, foi responsável por financiar significativo aporte de tecnologia mecânica no campo nos últimos anos. O setor de produção de máquinas agrícolas beneficiou-se com a expansão das vendas, em especial, nos estados do Rio Grande do Sul, São Paulo, Paraná e Minas Gerais, responsáveis por 48,5\%, 25,1\%, 22,9\% e 
$3,5 \%$, respectivamente, da produção das 66.210 unidades em 2009 (ANFAVEA, 2010).

Neste sentido, a estabilidade econômica, as novas tecnologias, as políticas de crédito e estímulo à renovação de frota e o aumento no preço da soja (condição verificada nos últimos anos), são variáveis que facilitam a aquisição dos equipamentos e modernização da atividade sojícola, o que limita os efeitos da alta concentração de mercado, no segmento de máquinas agrícolas, para a competitividade do elo central da cadeia produtiva.

\subsection{Segmento de Comércio e Processamento da Soja}

A agroindústria brasileira de produção de óleos vegetais é composta por 108 unidades de processamento de grãos, das quais, 94 utilizam exclusivamente soja como matéria-prima e, seis, além da soja, extraem óleo de canola, girassol, babaçu e algodão. Dessas, 92 unidades fazem a extração do óleo por solvente (ABIOVE, 2011a).

"A extração por solvente é o processo mais eficiente, pois aumenta o rendimento do óleo na extração da soja, proporcionando uma economia de energia, de consumo de solvente e mão-de-obra" (THOMAS, 2003. p. 7). Nesse processo, "o aproveitamento médio do grão é de $79 \%$ de farelo e $19,8 \%$ de óleo bruto" (PAULA; FAVERET FILHO, 1998. p. 14). Isso demonstra que a tecnologia utilizada para a extração de óleo no Brasil é semelhante a da indústria dos países concorrentes.

Atualmente, a extração de óleo e farelo está concentrada em plantas com capacidade superior a 1.500 t/dia: aproximadamente $47 \%$ das unidades produtivas possuem capacidade para processar de 1.500 a $2.999 \mathrm{t} /$ dia e; $26 \%$ das plantas apresentam capacidade de processamento de soja superior a $3.000 \mathrm{t} / \mathrm{dia}$. As plantas menores, com capacidade de até $599 \mathrm{t} / \mathrm{dia}$ e no intervalo entre 600 e 14.499 t/dia representam, respectivamente, $3 \%$ e $24 \%$ do total de plantas industriais (ABIOVE, 2011a).

Operando em plena capacidade, a indústria possui capacidade de processamento de 165.299 toneladas de soja em grão por dia (ABIOVE, 2011a). Esse montante equivale à produção de 56,47 mil hectares de área plantada de soja (considerando uma produtividade média de $2.927 \mathrm{~kg} / \mathrm{h}^{4}$ ). Sendo assim, trabalhando apenas nos dias úteis ${ }^{5}$ e turno único, a agroindústria processadora brasileira possui capacidade de processar a produção de 14,17 milhões de hectares, o que representou $65 \%$ da área plantada de soja no Brasil em 2009.

Dado o padrão tecnológico do processo e o grande volume de capital exigido para a entrada de novas empresas na indústria de processamento de grãos, espera-se que a estrutura de mercado continue com elevados níveis de concentração. No Brasil, as tradings Algar Agro S.A., ADM Brasil Ltda., Amaggi Exportação e Importação Ltda., Baldo S.A., Bunge Alimentos S.A., Cargill

\footnotetext{
${ }^{4}$ A produtividade média da lavoura de soja, estimada pela Conab (2011) foi de $2.927 \mathrm{~kg} / \mathrm{ha}$.

${ }^{5} \mathrm{Em} 2009$, foram 251 dias úteis, considerando os feriados nacionais e finais de semana.
} 
Agrícola S.A., Imcopa Importação Exportação e Indústria de Óleos Ltda., Louis Dreyfus Commodities Brasil S.A., Óleos Menu Indústria e Comércio Ltda. são responsáveis por cerca de $72 \%$ do volume processado de soja (ABIOVE, 2011b).

O processo de concentração intensificou-se a partir de 1995, principalmente por meio de fusões e aquisições.

Essa tendência pode ser explicada por várias circunstâncias, entre as quais, as estratégias de expansão, que se baseiam em fusões e aquisições por considerar que essas proporcionam a abertura de novos mercados e a redução de riscos. Nesta perspectiva, o crescente processo de concentração, via incorporação de novas unidades à estrutura organizacional, permite alargar o horizonte de diversificação e possibilita a continuidade do crescimento (BRITTO, 2002).

O poder de mercado das principais empresas do segmento é relevante, uma vez que as sete maiores empresas possuem $67,40 \%$ do o market share da comercialização de soja (Tabela 6).

Tabela 4. Market Share das empresas que comercializaram soja no Brasil: 2006

\begin{tabular}{|c|c|c|}
\hline \multirow[b]{2}{*}{ Empresa } & Comercialização & \multirow[b]{2}{*}{ Market Share } \\
\hline & $\begin{array}{ll}(\mathrm{em} & \mathrm{R} \$ \\
\left.1.000 .000^{\star}\right) & \end{array}$ & \\
\hline Bunge Alimentos S.A. & $4.113,91$ & $24 \%$ \\
\hline Cargill Agrícola S.A. & $2.571,19$ & $15 \%$ \\
\hline ADM do Brasil Ltda. & $2.571,19$ & $15 \%$ \\
\hline Louis Dreyfus Commodities Brasil Ltda. & $1.199,89$ & $7 \%$ \\
\hline Grupo Agrenco & 857,06 & $5 \%$ \\
\hline Noble Group & 171,41 & $1 \%$ \\
\hline Coimex Trading & 68,57 & $0,4 \%$ \\
\hline Outros & $5.588,06$ & $32,6 \%$ \\
\hline Total & $17.141,29$ & $100 \%$ \\
\hline $\mathrm{RC}_{4}$ & $10.456,19$ & $61 \%$ \\
\hline $\mathrm{RC}_{7}$ & $11.553,23$ & $67 \%$ \\
\hline
\end{tabular}

Fonte: BRASIL (2007b).

* Estimativa de comercialização calculada a partir do Market Share das empresas sobre o valor da produção de soja em 2006, Censo Agropecuário 2006 (IBGE, 2010).

Nesta perspectiva, observa-se que os principais segmentos da cadeia estão sob o controle de um seleto grupo de empresas oligopolistas e, em muitos casos, com poder de monopsônio também.

\section{CONCLUSÕES}

Confirmou-se a hipótese de que as empresas que fornecem insumos e demandam a produção do agricultor operam com elevado poder de mercado e que as mesmas, protegidas por barreiras à entrada, podem exercer seu poder 
de mercado e deslocar o ponto de equilíbrio para uma situação que tenda a maximizar a lucro da empresa, em detrimento da acumulação de capital do produtor rural.

A consolidação do oligopólio nos elos à montante da produção e do oligopsônio no elo à jusante submete o produtor a negociar numa perspectiva desfavorável. Por estarem protegidas pelas fronteiras tecnológicas de seus produtos, legislação e, em muitos casos, serem subsidiárias de agroindústrias processadoras de soja, o poder de mercado pode ser facilmente exercido.

No segmento de processamento de grãos, formado por cooperativas e empresas que exercem o controle mundial da informação, do mercado de insumos e de soja em grão, farelo e óleo, a concentração adquire consequências ainda maiores, sobretudo quando o mesmo grupo controla diferentes elos da cadeia produtiva. Nesta situação, o produtor rural de soja depende de insumos ofertados por uma indústria oligopolizada e oferta seus produtos para a agroindústria oligopsonizada.

Em função disso, muitos sojicultores operam sem opção de sucesso a não ser ampliar continuamente a escala de produção. $\mathrm{Na}$ busca pela continuidade e atuando como tomador de preços de insumos e de sua própria produção, os sojicultores utilizam a pressão por subsídios para garantir a continuidade da atividade. Esta é a prática das principais nações do mundo e resulta na apropriação da maior parte do excedente econômico pelas agroindústrias e em maiores gastos governamentais para atender as demandas setoriais da sojicultura.

O resultado deste tipo de integração produtiva conduz a perdas de competitividade empresarial e global deste, que é um importante segmento da economia agrícola brasileira. A consequência é que, neste cenário, a contribuição da produção de grãos para o desenvolvimento regional fica prejudicada, uma vez que os produtores têm sua renda diminuída e cada vez mais instável, o que se traduz em volatilidade para as economias das regiões cuja soja ocupa posição importante na matriz produtiva.

Portanto, cabe ao Estado brasileiro definir a forma de inserção dos agentes nacionais, em especial do produtor rural: se será caracterizado como um instrumento de acumulação do capital internacional ou se participará dos ganhos e se constituirá como agente de desenvolvimento regional.

\section{REFERÊNCIAS}

ABIFINA. Associação Brasileira das Indústrias de Química Fina, Biotecnologia e suas Especialidades. Estatísticas. 2012. Disponível em: < http://www.abifina.org.br/estatisticas.asp>. Acesso em: 18/12/2012.

ABIOVE. Associação Brasileira das Indústrias de Óleos Vegetais. Pesquisa da capacidade instalada 2009. São Paulo. 2011a.

ABIOVE. Associação Brasileira das Indústrias de Óleos Vegetais. São Paulo. 2011b. Disponível em <http://www.abiove.com.br/abiove_br.html> 
ABIQUIM - Associação Brasileira da Indústria Química. Anuário da Indústria Química Brasileira. São Paulo, 2008.

AENDA - Associação Brasileira dos Defensivos Genéricos. Produtos Defensivos Agrícolas: listagem completa, cultura a cultura, dos produtos registrados no Brasil: 2011. Disponível em http://www.aenda.org.br/new_produtos.htm

ANDA, Associação Nacional para Difusão de Adubos. Setor de Fertilizantes: anuário estatístico 2009. São Paulo, Comitê de Estatística. 2010.

ANFAVEA, Associação Nacional dos Fabricantes de Veículos Automotores. Anuário da indústria automobilística brasileira. São Paulo, 2010.

BANDT, J. Les filieres de production: mythe ou réalité. Economie ET PME. n. 3, 1982.

BANDT, J. La filiere comme méso-systeme. In. ARENA e al. Traité d'economie industrielle. Paris. Economica, 1988.

BRASIL. Secretaria de Acompanhamento Econômico. Ministério da Fazenda da República Federativa do Brasil. Parecer n.o 06533/2008/RJ. In. Versão Pública, Ato de Concentração 08012.008562/2008-30. 2007b. Disponível em Disponível <http://www1.seae.fazenda.gov.br/ittera/pdf/08012008562200830.pdf>.

em

BRASIL. Agência Nacional de Vigilância Sanitária. Monitoramento do mercado de agrotóxicos: observatório da indústria de agrotóxicos. 2010. Disponível em <http://portal.anvisa.gov.br/wps/wcm/connect/07ee7e0041d81501a0d9f5255d4 2da10/estudo_monitoramento.pdf?MOD=AJPERES>. Acesso em: 10/10/2011

BRASIL. Ministério da Fazenda. Secretaria de Acompanhamento Econômico. Panorama do mercado de fertilizantes. 2011a. Disponível em: < http://www.seae.fazenda.gov.br>. Acesso em: 15/02/2011.

BRASIL. Ministério da Agricultura Pecuária e Abastecimento. Fertilizantes. 2012c. Disponível em: < http://www.agricultura.gov.br/vegetal/fertilizantes>. Acesso em: 15/02/2012.

BRITTO, J. Diversificação, competência e coerência produtiva. In. KUPFER, David; HASENCLEVER, Lia. Economia Industrial. Rio de Janeiro. Ed. Elsevier. 15ª ed. 2002. Cap.14. p.307-343. 2002

CARVALHO JÚNIOR, L. C. A Noção de Filière: um instrumento para a análise das estratégias das empresas. Textos de Economia. v. 6, n. 1, 1995. p. $109-116$.

COSTA, N. L. Agronegócio e desenvolvimento econômico: uma análise da expansão da soja no cerrado brasileiro e das transformações socioeconômicas no Pólo Balsas/MA. 2008. 152 f. Dissertação (Mestrado em Planejamento do Desenvolvimento). Universidade Federal do Pará, 2008.

COSTA, N. L.; DE SANTANA, A. C. Poder de mercado e desenvolvimento de novas cultivares de soja transgênicas e convencionais: análise da experiência Brasileira. Revista de Ciências Agrarias (Brasil), 2013. 
COSTA, N. L.; BRUM, A. L. Aspectos recentes da economia da soja no Brasil. In: Brum, A. L.; Müller, P. K. Aspectos do agronegócio no Brasil. ljuí/RS:Unijuí, 2008. Cap.10, p.197-223.

DIAS, V. P.; FERNANDES, E. Fertilizantes: uma visão global sintética. Rio de Janeiro. BNDES Setorial, n. 24, p. 97-138, set. 2006. Disponível em < http://www.bndes.gov.br/SiteBNDES/bndes/bndes_pt/Institucional/Publicacoes/ Consulta_Expressa/Setor/Complexo_Quimico/200609_9.html>. Acesso em: 15/02/2012.

DUFOUR, R.; TORRE, A. Filieres et structures polaires. In. ADEFL. L'analyse de filière. Paris. Economica, 1985.

FERGUSON, P. R.; FERGUSON, G. J. Industrial economics: issues and perspectives. $2^{\text {nd }}$ Ed. New York University Press. 1994

FERnANDES, E.; GUIMARÃES, B. de A.; MATHEUS, R. R. Principais empresas e grupos brasileiros do setor de fertilizantes. BNDES Setorial, Rio de Janeiro, n. 29, p. 203-228, mar. 2009.

FLICK, U. Uma introdução à pesquisa qualitativa. trad. Sandra Netz. 2 ed. Porto Alegre: Bookman, 2004.

FRAGA, G. J.; MEDEIROS, N. H. A indústria de esmagamento na região de expansão da soja: uma releitura dos índices HHI e CR4. Anais do VIII Encontro de Economia da Região Sul - Anpec Sul 2005. 2005.

GONSALVES, E.; LEMOS, M. B. Padrão de inovação tecnológica na indústria de defensivos agrícolas brasileira. Revista de Economia e Agronegócio, v.9, n.1, p.1-28, jan./abr. 2011.

GOODMAN, David; SORJ, Bernardo; WILKINSON, John. Da lavoura às biotecnologias: Agricultura e Indústria no Sistema Internacional. Rio de Janeiro, Campus. 1989.

IBGE, Instituto Brasileiro de Geografia e Estatística. Censo Agropecuário 2006. 2010. Disponível em http://www.sidra.ibge.gov.br

IFA, International Fertilizer Industry Association. IFAdata. 2012. Disponível em: <http://www.fertilizer.org>. Acesso em: 15/01/2012.

IPEAData. Banco de dados. 2011. Disponível em: $<$ http://www.ipeadata.gov.br>. Acesso em: 15/02/2012.

KON, A. Economia industrial. São Paulo: Nobel, 1999.

MEDEIROS, N. H.; REIS, S. V. dos. Competitividade e concentração industrial na cadeia alimentar da soja. In.: Anais do XXXVII Congresso Brasileiro de Economia e Sociologia Rural. Foz do Iguaçú, ago., 1999.

MENDES, Judas Tadeu Grassi. Economia agrícola: princípios básicos e aplicações. $2^{\text {a }}$ ed. Curitiba: ZNT, 1998.

MENDES, Judas Tadeu Grassi; PADILHA JUNIOR, João Batista. Agronegócio: uma abordagem econômica. São Paulo: Pearson Prentice Hall, 2007. 370p.

MENDES, K.; FIGUEIREDO, J. C.; MICHELS, I. A Nova Economia Institucional e Sua Aplicação no Estudo do Agronegócio Brasileiro. 
Revista de Economia e Agronegócio. Volume 6, no 3, 2008. Disponível em: <http://www.economia-aplicada.ufv.br/revista/pdf/2008/3/Artigo02.pdf>. Acesso em: 16/03/2012.

MIRANDA, Evaristo Eduardo. A Embrapa e a agricultura de precisão. Embrapa Monitoramento por Satélite. 2004. Disponível em: < http://www.embrapa.br/imprensa/artigos/2000/artigo.2004-12-07.2399621753/>. Acesso em: 20/03/2012.

NEVES, Marcos Fava; ZYLBERSZTAJN, Decio; NEVES, Evaristo Marzabal. Agronegócio do Brasil. São Paulo. Ed. Saraiva, 2005. 152p.

NICOLELLA, A. C.; DRAGONE, D. S.; BACHA, C. J. C. Determinantes da demanda de fertilizantes no Brasil no período 1970 a 2002. Rio de Janeiro. RER. vol. 43, no 01, p. 81-100, jan/mar 2005. Disponível em: < http://www.scielo.br/pdf/resr/v43n1/25837.pdf>. Acesso em: 20/03/2012.

OJIMA, A. L. R; YAMAKAMI, A. Modelo de programação quadrática para a análise da movimentação logística e comercialização da soja brasileira. Eng. Agríc. Jaboticabal, v.26, n.2, p.552-560, maio/ago. 2006.

OLIVEIRA, Tulio Teixeira de. Quando $15 \%$ é mais que $85 \%$. São Paulo. Aenda-Associação das Empresas Nacionais de Defensivos. 2011. Disponível em: <http://aenda.org.br/new_quando.htm>. Acesso em 18/02/2012.

PAULA, S. R. de; FAVERET FILHO, P. Panorama do complexo soja. Rio de Janeiro. BNDES, $1998 . \quad$ Disponível em http://www.bndes.gov.br/SiteBNDES/bndes/bndes_pt/Institucional/Publicacoes/ Consulta_Expressa/Setor/Agroindustria/199809_5.html

PORTER, M. E. Vantagem competitiva: criando e sustentando um desempenho superior. Rio de Janeiro. Ed. Campus, $7^{\text {a }}$ ed. 1992.

PORTER, M. E. What is strategy? Harvard Business Review. NovemberDecember, 1996.

PORTER, M. E. Competição: estratégias competitivas essenciais. Rio de Janeiro. Ed. Campus, 1999. p.167-208.

POSSAS, Maria Silvia. Concorrência e competitividade: notas sobre estratégia e dinâmica seletiva na economia capitalista. Campinas: Unicamp, 1993. 232f. Tese (Doutorado em Economia). Universidade Estadual de Campinas. 1993.

RESENDE, Marcelo; BOFF, Hugo. Concentração industrial. In. KUPFER, David; HASENCLEVER, Lia (orgs). Economia Industrial. Rio de Janeiro. Ed. Elsevier. 15a ed. 2002. Cap.4. p.73-108.

SANTANA, Antônio Cordeiro de. A dinâmica do complexo agroindustrial e o crescimento econômico no Brasil. Viçosa: UFV, 1994. 302 f. Teses (Doutorado em Economia Rural). Universidade Federal de Viçosa, 1994.

SEVERINO, A. J. Metodologia do trabalho científico. $22 \mathrm{ed}$. Ver, e ampl. de acordo com a ABNT. São Paulo. Cortez, 2002.

SILVA, J. M. Impactos macroeconômicos do desempenho agropecuário. Revista de economia e agronegócio. n.3, p. 283-308, set/dez. 2008. 
TERRA, Fábio Henrique Bittes. A indústria de agrotóxicos no Brasil. 2008. 156p. Dissertação (Mestrado em Desenvolvimento Econômico). Universidade Federal do Paraná, Curitiba, 2008.

THOMAS, Gilberto Carlos. Análise teórico-instrumental da extração de óleo de soja em instalação industrial do tipo rotocell. 2003. $140 \mathrm{f}$. Tese de Doutorado (Programa de Pós-Graduação em Engenharia Mecânica). Universidade Federal do Rio Grande do Sul, 2003.

UNITED STATES OF AMERICA. U.S. Department of Justice and the Federal Trade Commission. Horizontal merger guidelines. 2010. Disponível em: $<$ http://www.justice.gov/atr/public/guidelines/hmg-2010.pdf>. Acesso em: 09/02/2012. 